\title{
Direito à Educação no Brasil e dívida educacional: e se o povo cobrasse?*
}

Alceu Ravanello Ferraro

Unilasalle

Correspondência:

Alceu Ravanello Ferraro

Rua Dona Laura, 924 ap. 2001

90430-090 - Porto Alegre - RS

e-mail: aferraro@unilasalle.edu.br

\section{Resumo}

Inicia-se tratando do direito à Educação no quadro dos direitos fundamentais da pessoa humana e do conceito de dívida educacional que decorre da não-realização do direito público subjetivo de cada cidadão e cidadã à Educação Fundamental completa, conforme estabelecido na Constituição de 1988. Utilizando como parâmetro a informação censitária sobre o número de anos de estudo concluídos com aprovação levantados no Censo 2000, estima-se que, nesse ano, o Estado brasileiro devia, aos 119,6 milhões de pessoas de 15 anos ou mais, a astronômica cifra de 325,5 milhões de anos de estudo não realizados na idade própria - uma média de quase três anos por pessoa. São projetados também os investimentos necessários em termos de professores e salas de aula/turno-ano para o resgate da dívida. Mostra-se ainda que a dívida estimada com base na Pesquisa Nacional por Amostra de Domicílios 2005 (316,4 milhões de anos de estudo devidos) representa uma diminuição muito pequena em relação ao Censo 2000. Por fim, aborda-se a questão dos atores ou agentes da efetividade do direito à Educação e dos instrumentos de exigibilidade que a legislação põe à disposição desses mesmos agentes. Conclui-se afirmando que está posto aí, para a sociedade em geral e para educadores e educadoras em particular, o grande desafio de despertar nas pessoas humildes a consciência de que elas efetivamente têm direito à Educação e de que dispõem de meios para cobrar do Estado esse direito.

\section{Palavras-chave}

Direito à educação - Dívida educacional - Brasil. 


\title{
Right to education in Brazil and the educational debt: what if the people actually demanded it?*
}

\author{
Alceu Ravanello Ferraro \\ Unilasalle
}

Contact:

Alceu Ravanello Ferraro

Rua Dona Laura, 924 ap. 2001

90430-090 - Porto Alegre - RS

e-mail: aferraro@unilasalle.edu.br

\begin{abstract}
We start by considering the right to Education within the framework of the fundamental human rights, and the ensuing concept of educational debt, which follows from the failure to enforce the subjective public right of each citizen to a complete Fundamental Education as established by the 1988 Brazilian Constitution. Based on the 2000 census information on the number of years of schooling successfully concluded, we estimate that in that year the Brazilian State owed to the 119.6 million people aged fifteen years or more the astronomical sum of 325.5 million years of study not accomplished at their proper time - an average of almost three years per person. We also calculate the investment in terms of teachers and classrooms/ shift-year necessary to settle this debt. We also show that the debt estimated from the National Survey by Household Sampling 2005 (316.4 million years of study) represents a very small reduction with respect to the 2000 Census. Lastly, we deal with the question of the actors or agents of the effectiveness of the right to Education and of the instruments of accountability place at their disposal by the legislation. The article concludes by affirming the great challenge put before society in general and educators in particular of producing in the simple folk the awareness that they effectively have a right to Education, and that they have the means of demanding their fulfillment by the State.
\end{abstract}

\section{Keywords}

Right to education - Educational debt - Brazil. 
Não é comum ouvir falar de dívida educacional. No entanto, o conceito de dívida não oferece dificuldade. Pode-se dizer que ele é de conhecimento universal e que sua aprendizagem independe de escolarização. A experiência, própria ou de pessoas próximas, encarrega-se de ensiná-lo, deixando, não raro, marcas profundas e indeléveis. Mesmo os 17,6 milhões de brasileiros e brasileiras de 10 anos ou mais, que o Censo 2000 classificou como não sabendo ler e escrever (analfabetos), sabem muito bem, geralmente por experiência própria, o que é dívida e o que é ser devedor. Com efeito, basta uma única prestação não paga - de um eletrodoméstico, de um par de sapatos ou de qualquer outra mercadoria ou serviço - para se experienciar a condição de devedor e se apreender, na prática, o conceito de dívida.

Agora, já não é de tão fácil entendimento para as pessoas comuns, do povo, o discurso de que elas são credoras de educação escolar do Estado. Ou então de que o Estado lhes deve tantos anos de escola(rização). Tal dificuldade resulta de um conjunto de circunstâncias aqui apenas nomeadas e que se procurará aprofundar no decorrer do texto.

Primeiro, o conceito de dívida educacional, ao colocar tantos cidadãos e cidadãs humildes na condição de credores frente ao Estado, inverte a posição habitual na relação. É óbvio que, tão desprovidas de educação escolar, assim como de tantas outras coisas no que concerne aos direitos sociais, essas pessoas terão dificuldade de se imaginar na condição de credoras. Ainda mais de credoras perante o Estado!

Segundo, o conceito de dívida educacional só ganha sentido na medida em que, efetivamente, a afirmação do direito à Educação seja secundada pela disponibilização dos meios ou instrumentos capazes de tornar efetivo esse direito, isto é, de obrigar o Estado a saldar a dívida. 0 povo sabe perfeitamente que o país paga religiosamente e continuará pagando, ao capital internacional e nacional, as dívidas financeiras contraídas. Terá, porém, mais dificuldade de entender - melhor, de acreditar - que o Estado possa ter a mesma atenção e a mesma presteza no pagamento das dívidas sociais, no caso - contraídas em relação ao cidadão e à cidadã comum.

Terceiro, o direito à Educação é apenas um dentre toda uma série de direitos que integram o conjunto dos direitos sociais, e estes, no contexto da globalização e da ideologia neoliberal, estão em baixa. Assim, a dita dívida educacional é apenas um dos componentes da imensa dívida social acumulada que, por sinal, a ideologia neoliberal não só não reconhece, como tenta sistematicamente desqualificar.

\section{A educação no quadro dos direitos fundamentais da pessoa humana}

Já disse que o direito à Educação integra o conjunto dos direitos sociais. Estes, por sua vez, constituem uma das diferentes gerações ou dimensões ${ }^{1}$ dos direitos fundamentais da pessoa humana. Falar em dívida educacional pública significa duas coisas: primeiro, que a Educação se transformou num serviço público; segundo, que o Estado deixou de assegurar a determinadas pessoas ou grupos de pessoas o serviço público chamado Educação. É a conjunção dessas duas condições - a Educação entendida como serviço público e a não universalização ainda desse serviço - que coloca o Estado na condição de devedor e o cidadão na de credor de escolarização. Por escolarização, se deve entender não só o acesso, mas também a continuidade bem-sucedida na escola.

Os direitos sociais não foram nem os primeiros nem os últimos direitos fundamentais a serem conquistados. Numa de suas conferências dedicadas a Alfred Marshall, publicadas originalmente em The Marshall Lectures, em 1949, Theodor H. Marshall (1967) distinguiu três gerações de direitos: os direitos civis, conquistados no século XVIII; os direitos políticos, no século

1. Alguns autores, como Fernando Astria (2005), falam em diferentes gerações de direitos fundamentais; outros, como Ingo W. Sarlet (2005), preferem falar em diferentes dimensões de direitos fundamentais. 
XIX; os direitos sociais, no século XX. Os juristas acrescentam, hoje, novas ordens de direitos fundamentais, como os direitos coletivos. Ingo W. Sarlet, em sua obra $A$ eficácia dos direitos fundamentais (2005), ordena os direitos fundamentais segundo quatro dimensões diferentes.

A primeira reúne os direitos civis e os direitos políticos. São direitos de cunho negativo, que afirmam e defendem os direitos dos indivíduos frente ao Estado. Ou então, que põem limites ao Estado frente aos indivíduos. São eles: o direito à vida, à liberdade, à propriedade e à igualdade (formal) perante a lei. Estes têm na liberdade o princípio central e articulador (Sarlet, 2005).

A segunda dimensão dos direitos fundamentais da pessoa humana compreende o conjunto dos direitos sociais, entre os quais o à Educação. Enquanto os de primeira dimensão (os direitos civis e políticos) têm como esteio o princípio da liberdade, os direitos sociais estão abraçados ao princípio da igualdade, o segundo dos três princípios da Revolução Francesa (Liberdade, Igualdade, Fraternidade). Trata-se aqui de direitos positivos, afirmativos, que determinam o comportamento do Estado na realização da justiça social, na criação das condições de participação no bem-estar social (Sarlet, 2005). Figurando a Educação na cabeça da lista, esses direitos aparecem reunidos logo num dos primeiros artigos da Constituição de 1988:

Art. $6^{\circ}$. São direitos sociais a educação, a saúde, o trabalho, a moradia, o lazer, a segurança, a previdência social, a proteção à maternidade e à infância, a assistência aos desamparados, na forma desta Constituição. (Tácito, 2004) ${ }^{2}$

Atria (2005), em seu artigo "Existem direitos sociais?", é contundente no que se refere à relação entre essas duas ordens de direitos. Diz ele: “Agora podemos, então, entender a aparição da 'segunda' geração de direitos frente à primeira: quem aceita a primeira faz como um gesto vazio, a menos que aceite também a segunda" (p. 22). Na realidade, estão aí em disputa dois princípios da Revolução Francesa: o princípio da liberdade, o qual, em diferentes momentos da história, foi erigido em bandeira ${ }^{3}$ por diferentes movimentos ultraliberais como, nos dias atuais, pelo neoliberalismo, e o princípio da igualdade material, não apenas formal, em que se apóiam os direitos sociais e que tanto incomoda os ultraliberais, desde Thomas Robert Malthus, no final do século XVIIl, a Herbert Spencer, no final do século XIX, e aos ideólogos e artífices do consenso de Washington, particularmente desde o último quartel do século $X X^{4}$. Todos eles tremeram e tremem ante qualquer ênfase discursiva ou programática - em favor da igualdade, que costumam confundir com socialismo, quando não com comunismo.

A terceira dimensão dos direitos humanos compreende os direitos de fraternidade e solidariedade. São os assim chamados direitos coletivos, centrados no terceiro princípio da Revolução Francesa, a fraternidade, e voltados para a proteção a grupos humanos (família, povo, nação...):

Dentre os direitos fundamentais da terceira dimensão consensualmente mais citados, cumpre referir os direitos à paz, à autodeterminação dos povos, ao desenvolvimento, ao meio ambiente e qualidade de vida, bem como o direito à conservação e utilização do patrimônio histórico e cultural e o direito de comunicação. (Sarlet, 2005, p. 57)

Vale ainda lembrar que integram uma quarta dimensão dos direitos fundamentais os direitos à democracia, à informação e ao pluralismo (Sarlet, 2005).

Tudo isso para situar o direito à Educação no quadro dos direitos sociais, e estes, no

\footnotetext{
2. Redação dada pela Emenda Constitucional $n^{\circ} 26$, de 2000, que incluiu 0 direito à moradia.

3. Lembre-se, a propósito, a conhecida frase de Karl Marx, no posfácio da segunda edição de 0 Capital (1996, livro 1, v. I, p.12): "Uns, astutos, ambiciosos e práticos, se engajaram sob a bandeira de Bastiat, o mais superficial e, por isso mesmo, o mais bem sucedido representante da economia vulgar apologética [...]."

4. Sobre isto, veja-se Ferraro (1997; 1999; 2005a).
} 
quadro mais amplo dos direitos fundamentais da pessoa humana. Falta examinar a relação entre direitos sociais, há décadas em baixa, e dívida social, em alta. É o conceituado geógrafo Milton Santos (2000) que nos oferece elementos preciosos nesse sentido. Em seu livro, Por uma outra globalização, o autor começa por mostrar a necessidade de se distinguir três mundos num só. Temos primeiramente a globalização como fábula - o mundo como querem que o vejamos. Trata-se de uma "ideologização maciça". Vem em segundo lugar a globalização como perversidade ou o mundo tal como ele é, com o desemprego crescente que se torna crônico; o salário médio em baixa; a fome e o desabrigo se generalizando em todos os continentes; novas enfermidades como a SIDA (AIDS) e velhas doenças retornando de modo triunfal; a educação de qualidade tornando-se cada vez mais inacessível etc. Em terceiro lugar, temos "o mundo como ele pode ser: uma outra globalização” (p. 21).

No entanto, o que mais interessa aqui é a discussão desenvolvida sobre o tema da pobreza. De acordo com o autor, na segunda metade do século XX, os países subdesenvolvidos chegaram a conhecer pelo menos três formas de pobreza e, paralelamente, outras tantas formas de dívida social. A primeira forma de pobreza, ele a chama de pobreza incluída: "uma pobreza acidental, residual, estacional, intersticial, vista como desadaptação local aos processos mais gerais de mudança, ou inadaptação entre condições naturais e condições sociais" (p. 69). Tratava-se de uma pobreza localizada, que não se comunicava a outros lugares. Nessa situação, “as soluções ao problema eram privadas, assistencialistas, locais, e a pobreza era freqüentemente apresentada como um acidente natural ou social" (p. 70).

Chegou então uma segunda forma de pobreza, chamada de marginalidade, que foi reconhecida e estudada como uma "doença da civilização”, produzida pelo próprio processo de divisão do trabalho, internacional ou interno, mas que podia ser corrigida - pensava-se pela ação dos governos por meio de políticas de bem-estar.
Bem diferente é a terceira forma de pobreza: "a pobreza estrutural, que de um ponto de vista moral ou político equivale a uma dívida social. Ela é estrutural e não mais local, nem mesmo nacional; torna-se globalizada, presente em toda parte do mundo." Sua produção é planetária, ainda que esteja mais presente nos países já pobres. Trata-se de uma pobreza de novo tipo, tanto pelo seu caráter de "pobreza estrutural globalizada”, quanto pelo fato de ser "resultante de um sistema de ação deliberada". Nessa última fase, "os pobres não são incluídos nem marginalizados, eles são excluídos”. A divisão do trabalho, antes mais ou menos espontânea, “obedece agora a cânones científicos [...], e é movida por um mecanismo que traz consigo a produção das dívidas sociais e a disseminação da pobreza numa escala global”. Trata-se de uma pobreza que é "produzida politicamente pelas empresas e instituições globais” (p. 69-72).

Avaliar e discutir a dívida educacional pública brasileira nos dias atuais implica na consideração atenta daquilo que se passa com os credores dessa dívida: em primeiro lugar, os pobres. 0 fato em si desse novo tipo de pobreza estrutural globalizada, identificado por Milton Santos, ao mesmo tempo em que reforça a importância estratégica do conceito de dívida educacional e de sua avaliação, coloca questões e desafios novos no que se refere ao terreno das políticas sociais em geral e das políticas educacionais em particular.

Vai na mesma direção a manifestação de Viviane Forester (1997), em seu livro O horror econômico:

A tendência, entretanto, é exatamente essa. Uma quantidade importante de seres humanos já não é mais necessária ao pequeno número que molda a economia e detém o poder. Segundo a lógica reinante, uma multidão de seres humanos encontra-se assim sem razão razoável para viver neste mundo, onde, entretanto, eles encontraram a vida. (p. 27)

Nas orelhas do referido livro de Forester (1997), Cony, depois de lembrar a exclusão de 
grande parte do gênero humano em nome da sacralidade do mercado, estarrece com as perguntas que levanta:

0 próximo passo será a eliminação? Caminhamos para um holocausto universal, quando a economia modernizada terá repugnância em custear a sobrevivência de quatro quintos da população mundial?

Importa agora examinar brevemente o caminho percorrido na construção do direito à Educação no Brasil, para depois enfrentarmos a questão da dívida educacional.

\section{O direito à Educação nas constituições brasileiras}

Para que uma pessoa - criança, adolescente, jovem ou adulto de qualquer idade possa constituir-se credora de educação escolar frente ao Estado ou, visto de outra forma, para que o Estado se veja posto na condição de devedor de educação escolar ou de escolarização e possa ser compelido à prestação do referido serviço, são necessárias duas coisas: primeiro, que haja o reconhecimento, no direito positivo, do direito universal ao serviço público chamado Educação; segundo, que os cidadãos sejam dotados de instrumentos eficazes de cobrança do referido direito. Essas duas condições juntas formam aquilo que, no Direito, se denomina direito público subjetivo. 0 reconhecimento desse direito em assunto de Educação data da Constituição de 1988. Como esclarece Konzen (1995), até 1988, a Educação era vista mais como uma necessidade e um dever do que propriamente como um direito. Considerada necessária ao desenvolvimento da sociedade, a Educação se impunha ao Estado como ideal político a ser alcançado, mas sem que the correspondesse, na contrapartida, de parte dos cidadãos, qualquer instrumento de exigibilidade. 0 dever do Estado de oferecer oportunidades de ensino não passava de uma norma de conteúdo meramente programático: uma boa intenção a ser cumprida na medida do possível. Nas palavras textuais do autor:
O educando, os pais, a comunidade, a sociedade como um todo, os destinatários do dever, diante da falta da vaga, diante da ausência de educação de qualidade, ficavam à mercê da vontade política para o atendimento de suas 'justas reivindicações', muitas vezes não atendidas, 'lamentavelmente', sob o signo da 'falta total de recursos'. (p.12)

A Constituição do Império do Brasil, de 1824, poderia parecer até generosa, para o tempo, quando estabeleceu que a instrução primária seria gratuita a todos os cidadãos. Escolas primárias gratuitas, mas quase inexistentes! De fato, a educação escolar esteve longe de ser afirmada como um direito social que se sustentasse por si mesmo. Ela aparece mais como um meio de garantir os direitos civis e políticos. É o que se depreende da leitura do texto constitucional:

Art. 179. A inviolabilidade dos direitos Civis e Políticos dos cidadãos brasileiros, que tem por base a liberdade, a segurança individual e a propriedade, é garantida pela Constituição do Império, pela maneira seguinte: [...] XXXIl. A instrução primária é gratuita a todos os cidadãos. (Nogueira, 2001, p. 103)

Decorrido quase meio século, o primeiro recenseamento, realizado em 1872, haveria de ferir os brios nacionais ao revelar ao mundo que o Brasil figurava entre os países campeões do analfabetismo: $82 \%$ de analfabetos entre as pessoas de cinco anos ou mais ou, aproximadamente, 78\% entre as pessoas de dez anos ou mais (Ferraro, 1985).

De 1872 para 1890, já na República, a situação se manteve inalterada quanto aos percentuais de analfabetismo para o conjunto do país. Em termos absolutos, no entanto, o número de analfabetos entre as pessoas de cinco anos ou mais aumentou muito nesses 18 anos, passando de 7,3 milhões em 1872 para 10,1 milhões em 1890 (Ferraro, 1985).

Apenas duas observações em relação à primeira Constituição republicana de 1891. De 
um lado, a Constituição foi simplesmente - e inexplicavelmente - omissa em relação à educação popular, primária. Os constituintes consideraram mais importante estabelecer a laicidade do ensino ministrado nos estabelecimentos públicos: “Art. 72. [...] $§ 6^{\circ}$. Será leigo o ensino ministrado nos estabelecimentos públicos" (Baleeiro, 2001). Em contraposição a isso, a República da Argentina passara a contar, desde a primeira metade da década de 1880 , com a poderosa Lei 1.420 , que marcou a diferença entre o desenvolvimento da Educação naquele país em relação ao Brasil. Weinberg (1984), em estudo introdutório aos dois volumes que contêm o debate parlamentar sobre o projeto que resultou na Lei 1.420, faz a seguinte avaliação:

Esta ley orgánica tuvo influencia decisiva en la formación de varias generaciones de argentinos; sus sabias e generosas previsiones han facilitado el mejoramiento del nivel cultural del país, en particular por la disminución sensible y permanente de los índices de analfabetismo; o expresado de otro modo, por el incremento paulatino de los índices de escolaridad. (v. 1, p. XVI)

Isso, apesar de que, segundo o autor, "muchas de sus postulaciones esenciales han sido transgredidas tanto en su letra como en su espiritu; otras, en cambio, no tuvieron la aplicación prevista por los legisladores" (p. XVI). A lei argentina talvez não tenha ido tão longe quanto a nossa primeira Constituição republicada na afirmação da laicidade. Em contrapartida, avançou enormemente no debate e na afirmação dos princípios da gratuidade e da obrigatoriedade da Educação Primária, avanço que, no Brasil, teria que aguardar mais meio século. Além disso, no Brasil, a Constituição republicana de 1891 foi draconiana em relação aos analfabetos, porquanto constitucionalizou a exclusão destes do direito ao voto, conforme fora estabelecido na reforma eleitoral conhecida como Lei Saraiva (Bonavides; Amaral, v. 2, 2002), de 1881, ainda no Império, exclusão essa que se manteve inabalável até o Emendão de $1985^{5}$ e a Constituição de 1988.

Foi necessário esperar pela Constituição de 1934 para que se pudesse ter algum avanço mais significativo na legislação constitucional brasileira. Esta estabeleceu que a Educação "é direito de todos e deve ser ministrada pela família e pelos poderes públicos". Definiu também que o Plano Nacional de Educação deveria obedecer, entre outras, às seguintes normas: “a) ensino primário integral e gratuito e de freqüência obrigatória, extensivo aos adultos; b) tendência à gratuidade do ensino educativo ulterior ao primário a fim de o tornar mais acessível [...]" (Art. 150, parágrafo único; Poletti, 2001). Apesar desse avanço declaratório e de cunho programático, é pelo menos cinqüentenária a manifestação de juristas brasileiros de renome, como Pontes de Miranda ${ }^{6}$ (1960), sobre a ineficácia de qualquer afirmação do direito à Educação que não venha acompanhada de instrumentos que permitam, a cada cidadão e a cada cidadã, cobrar do Estado, com presteza e eficácia, esse direito. Foi o que aconteceu com o direito à Educação na Constituição de 1934, cujo artigo 149 limitava-se a afirmar que "a educação é direito de todos e deve ser ministrada pela família e pelos poderes públicos [...]", sem oferecer instrumentos de cobrança do referido direito. As constituições seguintes - de 1937, 1946 e 1967 e suas emendas - pouco acrescentaram ao direito à Educação como definido na Constituição de 1934. A limitada eficácia de tal direito pode ser avaliada pela evolução do número de pessoas de dez anos ou mais não alfabetizadas no Brasil, o qual continuou crescendo: 16,5 milhões em 1940, 18,8 milhões em 1950, 19,4 milhões em 1960, 21,6 milhões em 1970 , até atingir o nível máximo de 22,4 mi-

5. Emenda Constitucional n. 25, de 15 de maio de 1985, a qual determinava, no Art. 147, § 40: "A lei disporá sobre a forma pela qual possam os analfabetos alistar-se eleitores e exercer o direito de voto" (Cavalcanti; Brito; Baleeiro, 2001).

6. Para o autor, o Direito, no sentido objetivo, "é a regra a que devem obedecer atos humanos, para que produzam certos efeitos, ou que atribui certos efeitos a fatos e atos, relevantes para a vida humana." Já o direito subjetivo "é todo o direito de que a regra objetiva dota os sujeitos de direito, conferindoIhes projeção própria, e atuação voluntária, ou não" (p. 112, grifos do autor). 
lhões em 1980 (IBGE, 1940, 1950, 1960, 1970 e 1980), justamente na abertura da década do processo de redemocratização e da Constituinte de 1987/1988).

No entanto, o que tem de novo a Constituição de 1988? Dá-se novamente a palavra ao Procurador de Justiça Afonso Armando Konzen (1995), que teve participação destacada, no Rio Grande do Sul, em 1995, no projeto $O$ direito é aprender ${ }^{7}$. Segundo o autor, o quadro normativo alterou-se completamente a partir de 1988:

A Constituição Federal elevou a educação à categoria de direito público e, para a criança e o adolescente, a educação fundamental ao nível de direito público subjetivo e indisponível. (p. 12, grifos meus)

É o que se tem nos artigos 205 e 208 da Constituição Federal de 1988 (Tácito, 2001):

Art. 205. A educação, direito de todos e dever do Estado e da família, será promovida e incentivada com a colaboração da sociedade, visando ao pleno desenvolvimento da pessoa, seu preparo para o exercício da cidadania e sua qualificação para o trabalho.

Art. $208^{8}$. 0 dever do Estado com a educação será efetivado mediante a garantia de:

1 - ensino fundamental, obrigatório e gratuito, assegurada, inclusive, sua oferta gratuita para todos os que a ele não tiveram acesso na idade própria;

11 - progressiva universalização do ensino médio gratuito;

111 - atendimento educacional especializado aos portadores de deficiência, preferencialmente na rede regular de ensino;

IV - atendimento em creche e pré-escola às crianças de zero a seis anos de idade;

$\mathrm{V}$ - acesso aos níveis mais elevados do ensino, da pesquisa e da criação artística, segundo a capacidade de cada um;

Vl - oferta de ensino noturno regular, adequado às condições do educando;
V11 - atendimento ao educando, no ensino fundamental, através de programas suplementares de material didático-escolar, transporte, alimentação e assistência à saúde.

$\S 1^{\circ}-0$ acesso ao ensino obrigatório e gratuito é direito público subjetivo.

$\S 2^{\circ}$ - 0 não-oferecimento do ensino obrigatório pelo Poder Público, ou sua oferta irregular, importa responsabilidade da autoridade competente.

$\S 3^{\circ}$ - Compete ao Poder Público recensear os educandos no ensino fundamental, fazer-lhes a chamada e zelar, junto aos pais ou responsáveis, pela freqüência à escola.

Segundo Tácito (2001), a Educação e a Cultura teriam figurado apenas simbolicamente nas Constituições do Império (1824) e da Primeira República (1891). Somente a partir da Constituição de 1934, se teria inaugurado nova perspectiva no que concerne a estas: "[...] a par da continuidade dos direitos individuais e das liberdades públicas, a tendência de abertura para as questões sociais transporta para o âmbito das Constituições o direito à Educação e à difusão da Cultura, que passa a ser regulado em capítulos especiais" (p. 34). No entanto, o autor parece não dar muita importância à afirmação do caráter público subjetivo do direito à Educação na Constituição de 1988. Segundo ele, a Constituição não teria introduzido inovações profundas, mas apenas elevado à hierarquia constitucional "princípios e normas até então contidas na legislação básica de diretrizes da Educação Nacional” (p. 34). Esse constitucionalista parece não concordar com a posição histórica de autores que, desde as constituições de 1934 e 1946, vinham sustentando a necessidade de se dar ao direito à Educação o caráter de direito público subjetivo, sem o que tal direito ficaria privado de eficácia por falta dos meios para cobrar do Estado a prestação do ser-

7. Projeto promovido cooperativamente pela Federação das Associações dos Municípios do Rio Grande do Sul (FAMURS), Associação dos Juízes do Rio Grande do Sul (AJURIS), Associação do Ministério Público do Rio Grande do Sul (AMPRGS) e Fundo das Nações Unidas para a Infância (UNICEF), com o apoio da Secretaria de Educação do Estado do Rio Grande do Sul.

8. Redação dada pela Emenda Constitucional n. 14, de 1996. 
viço chamado Educação. Aliás, já em 1933, em seu livro $O$ direito à educação, o constitucionalista Pontes de Miranda defendera decididamente a necessidade de dar ao direito à Educação o caráter de direito público subjetivo:

Vimos que o movimento do Estado para educar a população cria situação jurídica objetiva, e não direito público subjetivo. Quando os nossos professores recusam a matrícula a centenas de milhares de crianças que se apresentam, dão o exemplo de Estado em que a escola pública não é direito público subjetivo, e sim ato administrativo, falível, do Estado. Ora, o que hoje se requer é o Estado com tal dever, implícito no seu fim revolucionário (Rússia) ou que consagre o direito hegeliano à educação, direito público subjetivo (Alemanha, Áustria etc.). A solução que é urgente para o Brasil põe-se entre as duas tendências: o direito à educação direito público subjetivo e fim preciso do Estado; a ação do indivíduo contra o Estado e o plano de educação como essencial à existência do Estado, em cujo fim único está incluída a função única de educar. (p. 23, grifos do autor, ortografia atualizada) ${ }^{9}$

Retornando ao texto já citado de Konzen, podem ser destacados três pontos que parecem fundamentais sobre o direito à Educação na Constituição de 1988. Primeiro, a Constituição inovou, sim, elevando o direito à Educação de seu caráter meramente declaratório e programático à condição de direito público subjetivo, conforme se viu acima. Segundo, ficou superada a perplexidade de não se poder aplicar a lei sob a alegação de falta de regulamentação. De acordo com o autor, a regulamentação existe, porém, não nas normas que regem os sistemas de ensino, e sim no diploma legal que regulamenta os demais direitos da criança e do adolescente, isto é, no Estatuto da Criança e do Adolescente (Lei federal n. 8069, de 13 de julho de 1990) (Tapai, 2004). Para o autor,

[...] não é por falta de normas que não há o respeito aos direitos e garantias constitu- cionalmente reconhecidos. 0 que perturba é como fazer as normas funcionar. Ou seja, no caso, como tornar efetivo o direito à educação? Qual é a responsabilidade de cada um? [...] Quais são os instrumentos de exigibilidade? (Konzen, 1995, p. 12-13)

Com isso, pode-se passar a tratar do cálculo da dívida educacional.

\section{Definindo o parâmetro para o cálculo da dívida}

Antes de medir o montante da dívida educacional, será necessário dizer como se a medirá.

Utilizar-se-á como parâmetro ou critério o conjunto dos oito anos de Educação Fundamental ${ }^{10}$ assegurados pela Constituição Federal como direito público subjetivo, conforme estabelecido no inciso 1 e parágrafos $1^{\circ}$ e $2^{\circ}$ do artigo 208, já referidos. Assim, a dívida educacional do Estado - seja no âmbito federal, no estadual ou no municipal - será constituída pelo número de anos de estudo que estejam faltando a cada cidadão e cidadã em particular e ao conjunto deles e delas para atingirem esse mínimo de oito anos de estudo assegurados pela Constituição, ou seja, para chegarem à conclusão do Ensino Fundamental.

É claro que a dívida educacional poderia ser avaliada também em relação aos demais níveis, como o acesso à Educação Infantil e ao Ensino Médio, componentes inicial e final da Educação Básica. Basta lembrar o que a Constituição estabelece a respeito: “Art. 208. 0 dever do Estado com a educação será efetivado mediante a garantia de: [...] 11 - progressiva universalização do ensino médio; [...] IV - atendimento em creche e pré-escola às crianças de zero a seis anos de idade" (Tácito, 2001). No entanto, como já foi dito, considera-se aqui apenas o mínimo consti-

9. Veja também, de Pontes de Miranda, Comentários à Constituição de 1946, v. V (1953).

10. A Lei Federal $n$. 11.274, de 6 de fevereiro de 2006, elevou para nove anos 0 Ensino Fundamental, com início aos seis anos e prazo de implantação até 2010. 
tucional: os oito anos de ensino obrigatório e gratuito que compõem o Ensino Fundamental, conforme 0 já referido inciso 1 e parágrafos $1^{\circ} \mathrm{e}$ $2^{\circ}$ do artigo 208 da Constituição Federal.

A essa altura, poder-se-ia perguntar por que recorrer à informação censitária referente a anos de estudos concluídos com aprovação para o cálculo da dívida educacional. A resposta é simples: nenhuma das outras informações sobre Educação levantadas nos censos e nas Pesquisas Nacionais por Amostra de Domicílios - PNADs (saber ou não saber ler e escrever, grau concluído e grau e série freqüentados) - se prestaria para o objetivo em vista. Já a informação sobre anos de estudo concluídos permite avaliar quantitativamente, para cada pessoa, em termos de uma variável contínua, composta de anos de estudo, tanto a escolarização realizada, quanto a escolarização em haver. Estranhamente, essa informação tem sido relativamente pouco utilizada nas pesquisas em Educação.

Falta esclarecer a forma como se trabalhará com a informação anos de estudo. 0 1BGE estabelece cinco categorias de pessoas com base no número de anos de estudo, que são aqui interpretadas em termos de níveis de letramento:

Como esclarece Soares (1998), alfabetizar é a ação de ensinar a ler e escrever, e alfabetização designa a ação de alfabetizar, isto é, de ensinar a alguém a técnica de ler e escrever, e o termo letramento, tradução da palavra inglesa literacy, “é a condição de ser letrado", ou seja, "designa o estado ou condição daquele que é litarate, daquele que não só sabe ler e escrever, mas também faz uso competente e freqüente da leitura e da escrita" (p. 31-36). A tentativa de construção de níveis de letramento com base nos dados censitários sobre anos de estudo apóia-se no pressuposto de uma relativa correspondência entre anos de estudo e esses níveis de letramento ${ }^{11}$. Obviamente, a nãoverificação desse pressuposto resultaria no agravamento proporcional da dívida educacional que se estimará.

A primeira categoria estabelecida pelo IBGE reúne todas as pessoas sem instrução e com menos de um ano de estudo, o que corresponde aproximadamente, em termos conceituais e numéricos, à condição de analfabetismo absoluto, ou seja, à condição de não saber ler e escrever. Numa sociedade letrada, mesmo esse grupo não seria de todo iletrado. No entanto, seria exagero situá-lo no nível 1 de letramento. Optou-se, por isso, por manter a denominação "Sem instrução e menos de um ano de estudo".

A categoria "1 a 3 anos de estudo" costuma ser avaliada como equivalente à condição que a UNESCO denomina analfabetismo funcional, aqui entendida como a realização do mínimo dos mínimos em termos de letramento, por isso denominada nível 1 de letramento.

A categoria "4 a 7 anos de estudo", equivalente ao conceito de alfabetização funcional, é denominada nível 2 de letramento e é entendida como representando a realização do mínimo operacional no que se refere à capacidade e prática da leitura, da escrita e do cálculo. As três categorias até aqui referidas situam-se abaixo do mínimo constitucional (Educação Fundamental completa).

A categoria "8 a 10 anos de estudo", denominada nível 3 de letramento, compreende o Ensino Fundamental completo até Médio incompleto, ou seja, a realização do mínimo constitucional.

11. Foi no estudo "Analfabetismo e níveis de letramento no Brasil: o que dizem os censos?" (Ferraro, 2002), que integrou o Dossiê "Letramento", organizado por Magda Soares (Educação \& Sociedade, v.23, n.81, dez. 2002), que tentei construir níveis de letramento com base na informação censitária relativa a número de anos de estudo concluídos com aprovação.

\begin{tabular}{|l|l|}
\hline Categorias de anos de estudo (IBGE) & Correspondentes níveis de letramento \\
\hline Sem instrução e menos de 1 ano & Sem instrução e menos de 1 ano \\
\hline 1 a 3 anos & Nivel 1 de letramento \\
\hline 4 a 7 anos & Nivel 2 de letramento \\
\hline 8 a 10 anos (Fundamental completo e Médio incompleto) & Nivel 3 de letramento \\
\hline $\begin{array}{l}11 \text { anos ou mais (Médio completo ou mais = Educação } \\
\text { Básica completa ou mais) }\end{array}$ & Nivel 4 de letramento \\
\hline
\end{tabular}


Por fim, a categoria "11 anos de estudo ou mais", dada como nível 4 de letramento, compreende a conclusão do Ensino Médio, ou seja, a realização da Educação Básica, pelo menos.

Para o cálculo da dívida educacional, serão consideradas as três primeiras categorias, que reúnem todas as pessoas de 15 anos ou mais que, no momento do censo, ainda não haviam conseguido realizar o mínimo constitucional de oito anos de Educação Fundamental. Note-se que a escolarização da população aqui considerada se deu antes e, por isso, não foi regida pela Lei Federal n. 11.274, de 6 de fevereiro de 2006, que elevou para nove anos o Ensino Fundamental.

0 passo seguinte será medir a dívida mediante o uso do parâmetro indicado. Antecipando o resultado, pode-se dizer que o Brasil chegou ao final do século $X X$ e ingressou no século $X X I$ com uma multimilionária dívida educacional que, apesar de todos os avanços buscados e em certa medida conseguidos, continua desafiando as boas intenções e principalmente os belos discursos dos governantes, da instância federal às instâncias estaduais e municipais.

\section{O montante da dívida educacional na virada de século}

Para o cálculo da dívida educacional total com base no critério do mínimo constitucional, será considerada toda a população de 15 anos ou mais recenseada no Censo 2000. Teoricamente, todas as pessoas de 15 anos ou mais poderiam deveriam! - ter concluído os oito anos do Ensino Fundamental até o momento do censo.

A Tabela 1 apresenta o conjunto dos 119.556.674 de pessoas de 15 anos ou mais, recenseadas no ano 2000, distribuídas por grupos de idade e pelo número de anos de estudo concluídos com aprovação, interpretados em termos de níveis de letramento. São destacados, a seguir, quatro grupos de pessoas quanto ao número de anos de estudo.

a) 0 primeiro grupo é composto pelas pessoas sem instrução e com menos de 1 ano de estudo, o que, conceitual e numericamente, pode ser considerado um equivalente muito próximo à condição de analfabetismo absoluto apurada no censo (não saber ler e escrever). 0 censo classifica nessa categoria aproximadamente 13,9 milhões de pessoas, cada uma delas credora de todas as oito séries de Ensino Fundamental (Tabela 1). À razão de oito anos de estudo por pessoa, a dívida educacional nesse primeiro grupo ultrapassa a casa dos 111,2 milhões de anos de estudo, divida essa concentrada nos grupos de mais idade, mas presente também nos grupos mais jovens (Tabela 2, coluna 2). Com efeito, somente para o conjunto de 1.439 .867 pessoas

Tabela 1: Pessoas de 15 anos ou mais de idade, por grupos de anos de estudo/níveis de letramento, segundo os grupos de idade. Brasil, 2000

\begin{tabular}{|c|c|c|c|c|c|c|c|}
\hline \multirow[b]{3}{*}{$\begin{array}{l}\text { Grupos de } \\
\text { idade }\end{array}$} & \multicolumn{7}{|c|}{ Pessoas de 15 anos ou mais de idade } \\
\hline & \multirow[b]{2}{*}{ Total } & \multicolumn{6}{|c|}{ Grupos de anos de estudo (Niveis de letramento) } \\
\hline & & $\begin{array}{c}\text { Sem instrução e } \\
\text { menos de } \\
1 \text { ano }\end{array}$ & $\begin{array}{l}1 \text { a } 3 \text { anos } \\
\text { (Nivel 1) }\end{array}$ & $\begin{array}{l}4 \text { a } 7 \text { anos } \\
\text { (Nivel 2) }\end{array}$ & $\begin{array}{l}8 \text { a } 19 \text { anos } \\
\text { (Nivel 3) }\end{array}$ & $\begin{array}{c}11 \text { anos ou } \\
\text { mais (Nivel 4) }\end{array}$ & $\begin{array}{c}\text { Não } \\
\text { determinados }\end{array}$ \\
\hline 15 anos & 3.528 .605 & 138.971 & 489.250 & 1.857 .603 & 1.001 .171 & - & 41.610 \\
\hline 16 a 17 anos & 7.198 .433 & 263.687 & 805.808 & 2.793 .123 & 3.084 .171 & 162.040 & 89.604 \\
\hline 18 e 19 anos & 7.222 .250 & 272.161 & 741.725 & 2.193 .112 & 2.373 .675 & 1.567 .020 & 74.558 \\
\hline 20 a 24 anos & 16.142 .935 & 765.048 & 1.870 .618 & 4.777 .302 & 3.465 .185 & 5.116 .239 & 148.543 \\
\hline 25 a 29 anos & 13.847 .499 & 811.508 & 1.793 .256 & 4.433 .993 & 2.433 .540 & 4.254 .842 & 120.361 \\
\hline 30 a 34 anos & 13.029 .101 & 956.812 & 1.870 .603 & 4.167 .277 & 2.169 .376 & 3.749 .212 & 115.821 \\
\hline 35 a 39 anos & 12.260 .820 & 1.003 .486 & 1.894 .513 & 3.858 .703 & 1.881 .977 & 3.519 .967 & 102.176 \\
\hline 40 a 49 anos & 19.273 .412 & 2.160 .463 & 3.446 .993 & 6.130 .141 & 2.480 .914 & 4.899 .801 & 155.098 \\
\hline 50 a 59 anos & 12.514 .631 & 2.506 .484 & 2.895 .555 & 3.713 .002 & 1.070 .596 & 2.212 .457 & 116.538 \\
\hline 60 a 69 anos & 8.191 .598 & 2.414 .924 & 2.074 .310 & 2.212 .533 & 510.412 & 897.795 & 81.624 \\
\hline 70 anos ou mais & 6.347 .390 & 2.611 .083 & 1.424 .001 & 1.433 .356 & 318.722 & 489.142 & 61.086 \\
\hline Total & 119.556 .674 & 13.904 .626 & 19.316 .632 & 37.570 .145 & 20.789 .738 & 26.868 .515 & 1.107 .019 \\
\hline
\end{tabular}

Fonte: IBGE, Censo Demográfico 2000. Resultados da amostra. 
de 15 a 24 anos, recenseadas no ano 2000 como "sem instrução e menos de 1 ano de estudo", a dívida educacional, à razão de oito anos de estudo por pessoa, montava a um total 11,5 milhões de anos de estudo.

b) A segunda categoria de análise é constituída por aquelas pessoas de 15 ou mais anos que, no Censo 2000, tinham apenas 1 a 3 anos de estudo realizados com aprovação, o que não representa mais do que a realização do mínimo dos mínimos em termos de estado ou condição de quem sabe ler e escrever, por isso denominado nível 1 de letramento. Encontravam-se nessa situação nada menos do que 19,3 milhões de pessoas, devendo-lhes o Estado, em média, seis anos de estudo por pessoa, chegando a 115,9 milhões o total de anos de estudo devidos a esse segundo grupo (Tabela 2, coluna 3).

c) A terceira categoria de credores de anos de estudo perante o Estado é constituída pelas pessoas, sempre de 15 anos ou mais, com 4 a 7 anos de estudo, com um crédito médio aproximado de 2,5 anos de estudo. Essas pessoas teriam atingido o mínimo operacional em termos de domínio e uso da leitura, da escrita e do cálculo na vida cotidiana. Como já se disse, essa situação é chamada de nível 2 de letramento, correspondendo aproximadamente àquilo que a
UNESCO chama de alfabetização funcional, termo que se tem evitado. 0 Censo contou nessa categoria quase 37,6 milhões de pessoas, em relação às quais o Estado acumulava uma dívida de 93,9 milhões de anos de estudo, à razão estimada de 2,5 anos de estudo por pessoa)

d) Resta 1,1 milhão de pessoas que não especificaram o número de anos de estudo (Tabela 2). Se lhes for atribuída a média generosa de 4 anos de estudo por pessoa, serão mais 4,4 milhões de anos de estudos devidos (Tabela 2 , coluna 4 ).

Agora, somando-se todos os anos de estudo devidos a essas diferentes categorias de pessoas de 15 anos ou mais que, no Censo 2000, não tinham concluído o Ensino Fundamental, chega-se ao astronômico número de 325,5 miIhões de anos de estudo devidos (Tabela 2). Uma dívida multimilionária!

Os níveis 3 e 4 de letramento não interessam para o estudo aqui desenvolvido por se referirem às pessoas que já haviam concluído pelo menos as oito séries do Ensino Fundamental.

\section{Pontos a esclarecer}

Antes de se passar à questão da "cobrança” da dívida, há mais pontos a esclarecer. 0

Tabela 2: Anos de escolarização não prestados/devidos às pessoas de 15 anos ou mais, sem educação fundamental completa, por niveis de letramento, segundo os grupos de idade. Brasil, 2000

\begin{tabular}{|c|c|c|c|c|c|}
\hline \multirow{3}{*}{ Grupos de idades } & \multicolumn{5}{|c|}{$\begin{array}{l}\text { Número de anos de estudo devidos, por grupos de anos de estudo (Níveis de } \\
\text { letramento) }\end{array}$} \\
\hline & $\begin{array}{l}\text { Sem instrução } \\
\text { e menos de } 1\end{array}$ & $\begin{array}{l}1 \text { a } 3 \text { anos } \\
\text { (Nível 1) }\end{array}$ & $\begin{array}{l}4 \text { a } 7 \text { anos } \\
\text { (Nivel 2) }\end{array}$ & $\begin{array}{c}\text { Não } \\
\text { determinados }\end{array}$ & \multirow{2}{*}{ Total } \\
\hline & $\times 8$ anos & $\times 6$ anos & $\times 2,5$ anos & $\times 4$ anos & \\
\hline 15 anos & 1.111 .768 & 2.935 .500 & 4.644 .008 & 166.440 & 8.857 .716 \\
\hline 16 a 17 anos & 2.109 .496 & 4.834 .848 & 6.982 .808 & 358.416 & 14.285 .568 \\
\hline 18 e 19 anos & 2.177 .288 & 4.450 .350 & 5.482 .780 & 298.232 & 12.408 .660 \\
\hline 20 a 24 anos & 6.120 .384 & 11.223 .708 & 11.943 .255 & 594.172 & 29.881 .519 \\
\hline 25 a 29 anos & 6.492 .064 & 10.759 .536 & 11.084 .983 & 481.444 & 28.818 .027 \\
\hline 30 a 34 anos & 7.654 .496 & 11.223 .618 & 10.418 .193 & 463.284 & 29.759 .591 \\
\hline 35 a 39 anos & 8.027 .880 & 11.367 .078 & 9.646 .758 & 408.704 & 29.450 .420 \\
\hline 40 a 49 anos & 17.283 .704 & 20.681 .958 & 15.325 .353 & 620.392 & 53.911 .407 \\
\hline 50 a 59 anos & 20.051 .872 & 17.373 .330 & 9.282 .505 & 466.152 & 47.173 .859 \\
\hline 60 a 69 anos & 19.319 .392 & 12.445 .660 & 5.531 .333 & 326.496 & 37.623 .081 \\
\hline 70 anos ou mais & 20.888 .664 & 8.604 .006 & 3.583 .390 & 244.344 & 33.320 .404 \\
\hline Total & 111.237 .008 & 115.899 .792 & 93.925 .363 & 4.428 .076 & 325.490 .239 \\
\hline
\end{tabular}

Fonte: Tabela 1. 
primeiro deles é que essa dívida em anos de estudo não cursados se distribui por toda a escala de idades, como se pode visualizar no Gráfico 1. Quase metade dessa dívida refere-se aos grupos etários constituídos por pessoas jovens e adultos relativamente jovens, distribuídos entre 15 e 39 anos. Não se pode, portanto, falar de dívida histórica no sentido de coisa do passado. Não! Grande parte da educação escolar não realizada é coisa atual, inclusive gerada no contexto da Constituição de 1988 . Basta lembrar a dívida de quase 8,6 milhões de anos de estudo devidos somente aos jovens que, na data do Censo 2000, tinha 15 anos de idade, os quais, na promulgação da Constituição, tinham apenas 3 anos.

0 segundo ponto é que, de um total de aproximadamente 119,6 milhões de pessoas de 15 anos ou mais, apenas 47,7 milhões haviam, na data do censo, concluído o Ensino Fundamental. Isso representa apenas 39,9\% do total (Tabela 2), o que atesta o baixíssimo nível de desempenho dos sistemas de Educação Fundamental no Brasil.

0 acesso à escola tem avançado sensivelmente a partir da década de 1980, particularmente a partir da primeira metade da década de 1990 . Com efeito, o total de não-freqüência na faixa de 7 a 14 anos, captado pelo IBGE em suas pesquisas, recuou sucessivamente de quase 7,6 milhões em 1980, para aproximadamente 5,7 milhões em 1991, 3,2 milhões em 1996, 1,5 milhões em 2000 e 0,8 milhões em 2004 (IBGE, 1980, 1991, 1996, 2000 e 2005). A esse respeito, em estudo recente, Oliveira e Araújo (2005) avaliam que, nos primeiros anos da década 2000, praticamente todas as pessoas com idade de freqüentar a escola estavam recebendo educação formal. Os autores vêem em tal fato uma indicação de que seria hora de se passar a refletir "exatamente sobre a qualidade como um direito daqueles que foram incorporados à escola nas últimas décadas" (p. 7-8). Concordase com os autores na ênfase que pretendem emprestar ao direito universal a uma educação de qualidade. Haveria, no entanto, que acrescentar que a questão do acesso não fica resolvida sim- plesmente porque as estatísticas oficiais dizem que a grande maioria, até a quase totalidade, das crianças e adolescentes de 7 a 14 anos está, hoje, matriculada em escola (como captado pelos censos escolares) ou está freqüentando escola (conforme colhido pelos censos demográficos e PNADs). Em primeiro lugar, a questão do acesso diz respeito também a todos os milhões de brasileiros e brasileiras de mais de 14 anos, que nunca freqüentaram ou que não conseguiram concluir as oito séries do Ensino Fundamental, coisa que a Constituição assegura a todos como direito público subjetivo, inclusive àqueles que não o puderam realizar na idade própria. Em segundo lugar, importa lembrar a necessidade de se trabalhar a questão da qualidade das estatísticas, o que envolve a discussão sobre as diferentes fontes de nossas estatísticas da Educação e os problemas de compatibilidade e comparabilidade dos resultados originados dos levantamentos censitários e amostrais, rea-lizados pela Fundação Instituto Brasileiro de Geografia e Estatística (IBGE), e dos censos escolares, realizados pelo Instituto Nacional de Estudos e Pesquisas Educacionais (INEP), do Ministério da Educação (MEC).

Os censos demográficos, assim como as contagens da população e as PNADs, realizados pelo IBGE, têm como fonte as pessoas entrevistadas a respeito de si e dos demais membros do domicílio. Já os censos escolares, realizados pelo INEP, têm como fonte os registros escolares de onde são retirados os dados que alimentam as planilhas de coleta do Censo Escolar. Ora, suspeita-se que um dos desafios para a pesquisa diga precisamente respeito aos (à qualidade dos) registros escolares. Estes equivalem, como fonte, aos registros civis ou vitais. Fontes distintas podem produzir estatísticas não imediatamente comparáveis e até discordantes. Pode-se ver sobre isso o artigo "Da universalização do acesso à escola e da qualidade das estatísticas" (Ferraro, 2004). Há também estudo inédito do autor, intitulado "Quando fantasminhas ocupam vagas" (Ferraro; Machado; Corrêa, 2004, inédito), que versa sobre o fenômeno da múltipla matrícula como estratégia familiar de acesso à escola ou à escola preferida. 
0 terceiro ponto refere-se ao volume de investimentos necessários para saldar a dívida educacional. 0 cálculo, aqui, apóia-se nos seguintes pressupostos: primeiro, uma média de 30 alunos por turma; segundo, inexistência de perdas por evasão ou repetência. As estimativas figuram na Tabela 3. 0 investimento, em termos de salas de aula, professores e tudo o mais que o processo de escolarização fundamental exige, seria o correspondente aos seguintes números de professores e turmas/turno-ano:

• 3,1 milhão de professores e turmas/turnoano para atender às pessoas de 15 a 39 anos; - 6,9 milhões de professores e turmas/turnoano para atender à população de 15 a 49 anos; - 8,5 milhões de professores e turmas/turnoano para atender à população de 15 a 59 anos; - 10,8 milhões de professores e turmas/turnoano para atender toda a população de 15 anos ou mais.

São contas para tirar o sono de qualquer administrador. É claro, se o povo decidisse cobrar a conta!

\section{Trajetória da dívida educacional do Censo 2000 à PNAD 2005}

Por último, resta saber quanto da conta o Estado conseguiu abater no qüinqüênio 20002005. A resposta à pergunta poderia desdobrarse em outra pesquisa e outro texto, principal- mente porque tal resposta demanda recorrer aos microdados da PNAD 2005, a mais recente disponível. Um processamento preliminar dos referidos microdados revela algumas coisas aqui apresentadas de forma bem esquemática, no sentido de se poder divisar a trajetória seguida, neste início de século XXI, pelo fenômeno aqui analisado sob o nome de dívida educacional. Algumas observações merecem destaque:

1. De 2000 para 2005, a população brasileira de 15 anos ou mais (aquela que interessa na pesquisa aqui em questão) aumentou de quase 119,6 milhões para aproximadamente 135,5 milhões de pessoas. Um aumento absoluto de quase 16 milhões.

2. Um dado positivo: o montante da dívida não acompanhou o crescimento da população. 3. Um dado preocupante: a dívida educacional que, no ano 2000, atingia a casa dos 325,6 milhões de anos de estudo devidos (Tabela 2) teve queda inexpressiva no qüinqüênio seguinte ao censo, ficando em 316,4 milhões no ano de 2005 (IBGE, 2005b). Isso representa uma queda de 3,2\% no período 2000-2005, o que se situa pouco acima de $0,6 \%$ ao ano. Uma dívida, se não eterna, com certeza só resgatável no muito longo prazo, salvo alguma mudança radical na política educacional.

Não encontraria, portanto, nenhum respaldo nos fatos a pretensão de ver, na crescente incorporação de crianças, adolescentes e

Tabela 3: Número de turmas e professores / turno - ano necessários para saldar a dívida

\begin{tabular}{|l|r|r|r|r|}
\hline \multicolumn{1}{|c|}{ Idade } & \multicolumn{5}{|c|}{ Anos de estudos devidos } \\
\hline 15 anos & 8.857 .716 & 8.857 .716 & 8.857 .716 & 8.857 .716 \\
\hline 16 a 17 anos & 14.285 .568 & 14.285 .568 & 14.285 .568 & 14.285 .568 \\
\hline 18 e 19 anos & 12.408 .650 & 12.408 .650 & 12.408 .650 & 12.408 .650 \\
\hline 20 a 24 anos & 29.881 .519 & 29.881 .519 & 29.881 .519 & 29.881 .519 \\
\hline 25 a 29 anos & 28.818 .027 & 28.818 .027 & 28.818 .027 & 28.818 .027 \\
\hline 30 a 34 anos & 29.759 .591 & 29.759 .591 & 29.759 .591 & \\
\hline 35 a 39 anos & 29.450 .420 & 29.450 .420 & 29.450 .420 & \\
\hline 40 a 49 anos & 53.911 .407 & 53.911 .407 & 53.911 .407 & \\
\hline 50 a 59 anos & 47.173 .859 & 47.173 .859 & & \\
\hline 60 a 69 anos & 37.623 .081 & & & \\
\hline 70 anos ou mais & 33.320 .404 & & & \\
\hline Total & 325.490 .239 & 254.546 .754 & 207.372 .895 & 94.251 .479 \\
\hline
\end{tabular}

* À razão de 30 alunos por turno e sem nenhuma reprovação/repetência 
jovens no sistema escolar, um abatimento significativo no montante da dívida educacional pública do Estado brasileiro à imensa massa de pessoas que deveriam ter completado, mas não conseguiram ainda integralizar sequer o mínimo constitucional representado pelos oito anos do Ensino Fundamental. Em 2004, ainda se encontravam nessa condição 50\% das pessoas de 15 anos ou mais. E o que é mais grave, nesse mesmo ano, a PNAD contava 1,05 milhão de jovens de 15 a 24 anos no grupo das pessoas sem instrução e com menos de 1 ano de estudo (IBGE, 2005a).

Em síntese, permanece, sim, de pé a questão do acesso à escola de parte daquelas pessoas que não puderam realizar ou concluir o Ensino Fundamental na idade própria.

Com isso, pode-se passar para o tema dos agentes e instrumentos de realização do direito à Educação.

\section{Atores e instrumentos de exigibilidade}

Os pais ou o responsável são os principais agentes da efetividade do direito à Educação. Cabe-lhes não só a efetivação da matrícula, mas também o controle da efetividade. Eles têm plena legitimidade ativa, tanto na esfera administrativa como em juízo. 0 Estatuto da Criança e do Adolescente (ECA) prevê medidas severas em caso de omissão ou negligência:

Art. 129. São medidas aplicáveis aos pais ou responsável: [...] V. obrigação de matricular o filho ou pupilo e acompanhar sua freqüência e aproveitamento escolar. (Brasil, Lei n. 8.069, 1990)

Em segundo lugar, entre os agentes da efetividade do direito à Educação, figura o Conselho Tutelar, serviço público, organizado e mantido pelo municipio. Compete-lhe:

[...] atender a criança ou o adolescente, assim como seus pais ou o responsável, toda vez que se afigurar uma situação de risco pessoal ou social, quer pela ação ou omissão da sociedade ou do Poder Público, pela falta, omissão ou abuso dos pais ou responsável, ou, ainda, em razão da própria conduta da criança ou adolescente. É o Conselheiro tutelar a porta de entrada do sistema de atendimento. (Konzen, 1995, p. 14)

Para o mesmo autor, criança sem escola, evadida da escola, com sintomas de maus tratos, com faltas injustificadas, com fraco aproveitamento escolar, com desvios de comportamento dentro da escola são situações de "risco pessoal ou social" (p. 15).

0 terceiro agente é o Ministério Público, com amplo poder de controle social sobre a regular oferta de Ensino Fundamental (Konzen, 1995). Com efeito, no ECA, lê-se que compete ao Ministério Público

[...] zelar pelo efetivo respeito aos direitos e garantias legais assegurados às crianças e adolescentes, promovendo as medidas judiciais e extrajudiciais cabíveis. (Brasil, Lei $\mathrm{n}$. 8.069, de 13.07.1990, Art. 201, inciso VII)

Temos, por fim, o papel da Tutela Judicial. Como observa Konzen (1995), se o ECA retirou do Poder Judiciário atribuições de caráter essencialmente assistencial, em contrapartida, devolveu-lhe "o papel clássico e indispensável, no caso, como a última instância garantidora dos direitos da cidadania infanto-juvenil” (p. 16).

\section{E se o povo cobrasse?}

Acreditará o povo que tem contas de educação escolar a cobrar do Estado? Poderão as pessoas humildes acreditar que o Estado está em dívida com elas e que elas têm o direito e dispõem dos meios para cobrar escola(rização)?

Está posto aí, certamente, um grande desafio para educadores e educadoras populares no sentido freireano, voltados/as para uma pedagogia conscientizadora e libertadora (Freire, 
1979). No caso, também para uma pedagogia da indignação (Freire, 2000). Por sua vez, o povo assim educado poderá tornar-se capaz de educar o Estado, no sentido que Marx (1977) deu à expressão em suas anotações críticas ao Programa de Gotha: “... es, por el contrario, el Estado el que necesita recibir del pueblo una educación muy severa" (p.31).

\section{Referências bibliográficas}

ATRIA, F. Existem direitos sociais? Revista do Ministério Público do Rio Grande do Sul, Porto Alegre, n. 56, p.9-46, set./dez. 2005.

BALEEIRO, A. Constituições Brasileiras: 1891. 2 ed. Brasília: Senado Federal e Ministério da Ciência e Tecnologia; Centro de Estudos Estratégicos, 2001. 121 p.: il. (Coleção: Constituições Brasileiras, v. 2).

BONAVIDES, P.; AMARAL, R. Textos políticos da história do Brasil. 3. ed. Brasília: Senado Federal, 2002. 10 v.

BRASIL. Lei federal n. 11.274. Disponível em <http://legislacao.planalto.gov.br/legislacao.nsf/Viw_Identificacao/lei11.2742006?0penDocument>. Acesso em: 6 fev. 2006.

CAVALCANTI, T. B.; BRITO, L. N. de; BALEIRO, A. Constituições Brasileiras: 1967. v. VI - A: Emendas Constitucionais Brasília: Senado Federal e Ministério de Ciência e Tecnologia, Centro de Estudos Estratégicos, 1999. (Coleção, Constituiç̧ões Brasileiras; v. Vla)

CONY, C. H. 0 novo holocausto. In: FORESTER, V. 0 horror econômico. São Paulo: Ed. Unesp, 1997.

ESTATUTO DA CRIANÇA E DO ADOLESCENTE e legislação correlata (Lei n. 8.069, de 13.07.1990). Obra coletiva da Editora Revista dos Tribunais, com a coordenação de Gisele de Melo Braga Tapai. Revista dos Tribunais, São Paulo, 2004.

FERRARO (FERRARI), A. R. Analfabetismo no Brasil: tendência secular e avanços recentes. Resultados preliminares. Cadernos de Pesquisa, São Paulo, n. 52, p. 35-49, fev. 1985.

FERRARO, A. R. 0 movimento neoliberal: gênese, natureza e trajetória. Sociedade em Debate, Pelotas/RS, v. 3, n. 9, p. 33-58, dez. 1997.

. Neoliberalismo e políticas sociais: um pé em Malthus, outro em Spencer. Universidade e Sociedade, Brasília, v. 9, n. 20, p. 15-20, set./dez. 1999.

. Analfabetismo e níveis de letramento no Brasil: o que dizem os censos? Educação \& Sociedade, Campinas, v. 23, n. 81, p. 21-47, dez. 2002.

. Da universalização do acesso à escola e da qualidade das estatísticas da educação. Cadernos de Educação, Pelotas/RS, v. 13, n. 23; p. 57-75, jul./dez. 2004.

Neoliberalismo e políticas sociais: a naturalização da exclusão. Estudos Teológicos, São Leopoldo/RS, v. 45, n. 1, p. 99 117, 2005a.

. Analfabetismo e alfabetização no Brasil: tendência secular e questões metodológicas. In: SANTOS, M. L. L. dos; DAMIANI, F. E. (Orgs.). Onde eles estão? Desvelando o analfabetismo no Brasil. Passo Fundo: UPF, 2005b. p. 49-79.

FERRARO, A. R.; MACHADO, N. C. F.; CORRÊA, C. C. Quando fantasminhas ocupam vagas. 0 fenômeno da múltipla matrícula em primeira série no município de Pelotas no ano 2000. 51 p. In: FERRARO, A. R. Diagnóstico da alfabetização e escolarização de crianças e adolescentes no Brasil segundo o Censo Demográfico 2000. Relatório Final - CNPq. São Leopoldo, abr. 2004.

FORESTER, V. 0 horror econômico. São Paulo: Ed. Unesp, 1997.

FREIRE, P. A pedagogia do oprimido. 6 ed. Rio de Janeiro: Paz e Terra, 1979. 
Pedagogia da indignação. Cartas pedagógicas e outros escritos. São Paulo: Ed. Unesp, 2000.

IBGE. Censo demográfico 1940, ...1950, ...1960, ...1970, ...1980, ...1991,... 2000.

. Contagem da população 1996.

Síntese de Indicadores 2004. Rio de Janeiro: IBGE, 2005.

Pesquisa Nacional por Amostra de Domicílios 2005.

KONZEN, A. A. A educação é direito. In: SEMINÁRIO ESTADUAL, 1995, Porto Alegre. Caderno de textos: 0 direito é aprender. Porto Alegre: FAMURS, AJURIS, AMPRGS, UNICEF, 1995. p. 12-16.

MARSHALL, T. H. Cidadania, classe social e status. Rio de Janeiro: Zahar, 1967.

MARX, K. Critica del Programa de Gotha. Moscú: Progreso, 1977. 56p.

0 capital: crítica da economia política. Livro 1, v. 1. 15 ed. Rio de Janeiro: Bertrand do Brasil, 1996.

MIRANDA, P. de. 0 directo à Educação. Rio de Janeiro: Alba, 1933.

Comentários á Constituição de 1946. Tomo V. 2. ed. rev. e aum. São Paulo: Max Limonad, 1953.

Comentários á Constituição de 1946. Tomo I. 3 ed. rev. e aum. Rio de Janeiro: Borsoi, 1960.

NOGUEIRA, 0. Constituições Brasileiras: 1824. 2 ed. Brasília: Senado Federal e Ministério da Ciência e Tecnologia, Centro de Estudos Estratégicos, 2001. 122p.: il. (Coleção: Constituições Brasileiras, v. 1).

OLIVEIRA, R. P. de; ARAÚJO, G. C. de. Qualidade do ensino: uma nova dimensão da luta pelo direito à educação. Revista Brasileira de Educação, Rio de Janeiro, n.28, p.5-23, jan./abr. 2005.

POLETTI, R. Constituições Brasileiras: 1934. 2 ed. Brasília: Senado Federal e Ministério da Ciência e Tecnologia, Centro de Estudos Estratégicos, 2001. 194p.: il. (Coleção: Constituições Brasileiras, v. 3).

SANTOS, M. Por uma outra globalização. São Paulo: Record, 2000.

SARLET, I. W. A eficácia dos direitos fundamentais. 5 ed. revista e ampliada. Porto Alegre: Livraria do Advogado, 2005.

SOARES, M. Letramento: um tema em três gêneros. 2 ed. Belo Horizonte: Autêntica, 1998.

TÁCITO, C. Constituições Brasileiras: 1934. 5 ed. Brasília: Senado Federal e Ministério da Ciência e Tecnologia, Centro de Estudos Estratégicos, 2001. 500 p.: il. (Coleção: Constituições Brasileiras, v. 7).

TAPAl, G. de M. B. (Coord.). Estatuto da Criança e do Adolescente e legislação correlata. São Paulo: Revista dos Tribunais, 2004. (Lei n. 8.069, de 13.07.1990).

WEIBERG, G. Estúdio preliminar. In: ARGENTINA. Lei 1420: 1883-1884 - Debate Parlamentario. Estúdio preliminar, selección y notas de Gregório Weinberg. 2 v. Buenos Aires: Centro Editor de América Latina, 1984. 359 p.

Recebido em 17.04.07

Aprovado em 16.06 .08

Alceu Ravanello Ferraro, professor do Programa de Pós-Graduação em Educação e do Curso de Pedagogia do Unilasalle, professor titular aposentado da UFRGS, pesquisador do CNPq, tem produzido principalmente sobre analfabetismo e escolarização no Brasil. 